\title{
Advance Research on Monitoring Of Soil \& Remote Sensing of Vegetation by Various Techniques for Proper Drip Irrigation
}

\author{
Aniket H. Hade, M.K. Sengupta \\ ( Department of EEE, PRMCEAM, Badnera, SGBA University, India )
}

\begin{abstract}
Vegetation is the key element which provides a vital foundation for all living things. An implementation of specific irrigation process by drip is very reasonable and capable. It is found that the various drip irrigation methods have been proposed are luxurious and dense to utilize. The remotely monitored embedded based irrigation system has become a new fundamental thing for a farmer which accumulates his energy, time and money and will reduce requirement of water. For better drip irrigation plan, this approach would utilize the soil test for the water content, the chemical constituent, and salinity and the fertilizer requirement data collected and processed by the wireless. The remote sensing replaces an expensive and the sluggish data collection on the ground, ensuring that the area or objects are not distributed due to this process. The optical \& Microwave remote sensing is less limited by climate and time and measure in large scale. The radiometric observations are also reviewed. The directional reflectance effects were modelled via a bidirectional reflectance distribution function (BRDF) acquires from high frequency multi-angular spectral observations. With this uniqueness, this technique becomes a valuable means to monitor soil moisture. This paper deal with various monitoring system and propose an automatic monitoring system model using Wireless Sensor Network (WSN) and also various remote sensing techniques for soil \& vegetation characteristics which will help the farmer to progress the yield.
\end{abstract}

Keywords : Angular Spectral Resolution, Dicke Radiometer, Drip irrigation, Data logger, Fertilizer, Hotspot, Microwave, Millimetre wave, Multiplexer, Remote sensing, Soil, sensors, ZigBee.

\section{Introduction}

The Irrigation is the artificial application of water to the soil for assisting in growing crops. Drip irrigation also known as micro irrigation \& is an irrigation method which minimizes the use of water \& fertilizer by allowing water to drip slowly to the roots of plants, either onto the soil surface or directly onto the root zone due to which a large quantity of water is saved $\&$ also the fertilizer which comes to the plant with the water. Indian agriculture is dependent on the monsoons, which is dependent on the nature and not a reliable source of water, so there is a need for an automatic irrigation system in the country which can provide water to the farms according to their moisture, temperature and soil types \& fertilizers. For a big farm land with horticulture activity the solution will be an automated system. Water contained in the soil is called soil moisture. And it is very important for plant growth. Water soluble fertilizer can be also applied without any wastage by this drip irrigation system. The advantage of using wireless sensors is to control all related parameters for better irrigation management.

Remote sensing is one of a set of tools available to land managers that provides up-to-date and the detailed information about land condition. It provides a cost-effective technique for mapping and monitoring broad areas. The uniqueness of satellite remote sensing lies in its ability to show large land areas and to detect features at electromagnetic wavelengths which are not visible to the human eye. Data from satellite images can show larger areas than aerial survey data and, as a satellite regularly passes over the same plot of land capturing new data each time, changes in the land use and condition can be routinely monitored. The information from remotely sensed images can be used in a number of ways for a number of purposes. It is usually combined with information from other data sources and on-the-ground observations, called ground truth.

Because of some limitations by traditional measurement methods, microwave remote sensing has been the most effective tool to monitor the soil moisture. Within microwave frequencies, the optical frequency for remote sensing of soil moisture is L-band $(\sim 1.4 \mathrm{GHz})$, for it have greater emitting depth and less effect on roughness and vegetation. The most important is that the soil moisture has the great relativity with the dielectric constant in this frequency. By correctly choosing sensor parameters, the effect of surface roughness can be reduced in some degree and by the data set at multi-frequency, polarization and incident angle, the model can be set up to eliminate of surface roughness and improves the system accuracy of monitoring surface moisture. By using multi-variable data fusion technique, the accuracy of retrieval should be improved. The microwave soil moisture monitoring theoretically depends on the distinct difference of dielectric constants between the liquid water and dry soil [46]. 
By the millimeter wave radiometric observations the vegetation growth and forecasting of crop growth can be predicted. In this paper, multi-angular and satellite based systems discussed. This paper gives a review of remote monitoring and control system based on existing technologies. The rest of the paper is organized as follows. Section II summarizes the literature review on the existing systems. Section III analyzes the main aim and prime objective of the automatic irrigation system. Section IV describes the proposed system \& applications. Finally, Section V deals with conclusion and future scope. And the last is the reference papers and publications.

\section{Literature Review}

After the research in the agricultural field, researchers found that the yield of agriculture goes on decreasing day by day. Use of technology in the field of agriculture plays important role in increasing the production as well as in reducing the extra man power efforts, water requirement and fertilizer requirement. Some of the researchers tried for betterment of farmers and provides the systems that use technologies which are helpful for increasing the agricultural yield. Some of such researches carried out in the field of agriculture are summarized below.

In Turkey, $75 \%$ of the current fresh water is consumed in the agricultural irrigation [15]. Therefore, efficient water management plays an important role in the irrigated agricultural cropping systems [26], [43]. A site-specific wireless sensor-based irrigation control system is a potential solution to optimize yields and maximize water use efficiency for fields with variation in water availability due to different soil characteristics or crop water needs and site-specific controlling irrigation valves [3],[11],[27]. Temporal monitoring of soil moisture at different growth stages of the crop could prevent water stress and improve the crop yield [10],[14]. A number of studies based on the relation between chlorophyll and water content have been carried out using remote sensing methods. These methods search for relationships between calculated vegetation indices and water content information [1],[4],[9],[16],[23],[38],[41].

Ge Jianjun.et.al. Summarized and analyzed various vegetation scattering models in soil moisture research by microwave remote sensing, and they suggested that the vegetation became the key factor which led to the nonlinear relationship between moisture and microwave signal. Disturbance of forest ecosystems including harvesting, fire, insect infestations, diseases, windfall, and die-back is an important component of the terrestrial carbon cycle [22],[28],[30],[37]. Disturbance events emit carbon to the atmosphere through oxidation and decomposition of dead organic matter, while, conversely, recovery from past disturbance tends to sequester carbon from the atmosphere, often over much longer time periods [30]. Study of the interactions between disturbance and carbon cycling has become of particular interest over recent years, as global warming is predicted to increase the frequency and severity of natural disturbance events [6],[28],[45],[53].

Researchers have typically assumed that the chlorophyll content of leaves or the degree of dying and drying out (also defined as degree of curing by [8]) were proportional to moisture content [4],[23], [39],[48]. This assumption may be correct for some species but cannot be generalized to all ecosystems. Variations in chlorophyll content can be caused by water stress but also by phonological status of the plant, atmospheric pollution, nutrient deficiency, toxicity, plant disease, and radiation stress [29].

In the last two decades, with the development of wireless technologies, several researches focused on autonomous irrigation with sensors in agricultural systems [36], [54]. The advantages of using wireless sensors are having the reduced wiring and piping costs, and easier installation and maintenance in large areas [2], [40],[52]. After the usage of wireless technology began in agricultural irrigation, a trial was made to involve different types of equipments in such instrumentations. In terms of controllers,[11],[12],[33] were designed microcontroller site-specific irrigation, wireless monitoring system was implemented with a field programmable gate array (FPGA) by [32].

In terms of protocols, infra-red, GSM/GPRS WPANs (Wireless Personal Area Networks), Bluetooth, WLANs (Wireless Local Area Networks) have been put to different utilities to implement wireless sensors in precision agriculture [5],[44],[51],[52]. Many studies have successfully demonstrated the use of active and passive microwave remote sensing too [17],[25],[50]. It has been seen that many irrigation scheduling methods by wireless sensors have been developed for the last several decades. Many of the commercially available sensors, valves and modules assembled for irrigation system networks are too complex and/or costly to be feasible for site-specific management of fixed irrigation systems.

\subsection{Aim}

\section{Aim \& Objectiv E}

The main aim of the research is to develop and to test an automation system having a low cost equipment and feedback type controller for site-specific management of irrigation systems and also to have a alternative power source like solar power or wind power. The data available from the various sensors will be 
received at the wireless base station for proper control, based on data. Data from radiometric observations and optical observations will be processed for need of irrigation with fertilizers.

\subsection{Objective}

The prime objective is to select the appropriate wireless network to collect the data from moisture sensors, water soluble fertilizer sensor placed in the field, temperature sensors of various areas of the field, pressure sensors in the irrigation system to monitor the proper drip of water along with the fertilizer which are kept in a separate tank.

Another addition of the proposed automation system is to install the digital cameras to monitor the plant growth and overall condition of the field. In addition, the developed irrigation method partly removes the excess workload of the farmers.

To install an optical observation and also radiometric observation system or getting the data from ISRO. To identify the suitable pump with facility for maintaining certain recommended pressure in the water pipe. To indentify proper sensors and monitoring device required for the farming data like soil moisture, soil temperature, soil fertilizer \& chemical constituents.

Search of appropriate sensors with specifications and coordinating wireless system for acquisition of various data. To process the data based on the limits set and there by controlling the whole irrigation management. To find the economic method of drip irrigation and its technique for automation regarding short term and long term crop.

\section{Proposed System \& Applications}

The betterment of agriculture depends on various environmental parameters such as soil temperature, soil moisture, relative humidity, $\mathrm{pH}$ of soil, light intensity, fertilizing property of the soil, etc. Any small changes in any of these parameters can cause problems like diseases, improper growth of plant, etc. mainly resulting in lesser yield.

There are number of techniques of doing the remote sensing for crop growth, vegetation growth and other related study for harvesting. The various methods have been used by On-field \& Off-field sensors to estimate surface soil moisture information using remote sensing as follows:

\section{Zigbee / HotSpot}

The block diagram of the proposed system of input unit is shown in Fig. 1 consists of different types of sensing unit such as Soil Moisture Sensor to measure water content of soil, Temperature Sensor detects the temperature, Humidity Sensor to measure the presence of water in air, Pressure Regulator Sensor to be selected for maintaining the recommended pressure, Molecular Sensor selected for better crop growth, Digital Camera with capability of tracking and taking photographs of the crop field to find the crop growth for measurement. The output of sensors are converted to analog using D/A converter at the transmitter input side and converted back to digital using A/D converter at the receiver output side. Multiplexer sometimes called Data selector is a combinational logic circuit that selects one of $2 n$ inputs and route it to the output. The data obtained from different types of sensors are transmitted to the Multiplexer using Wireless Sensor Network. ZigBee or Hotspot modules for wireless data transfer and receiving for control unit.

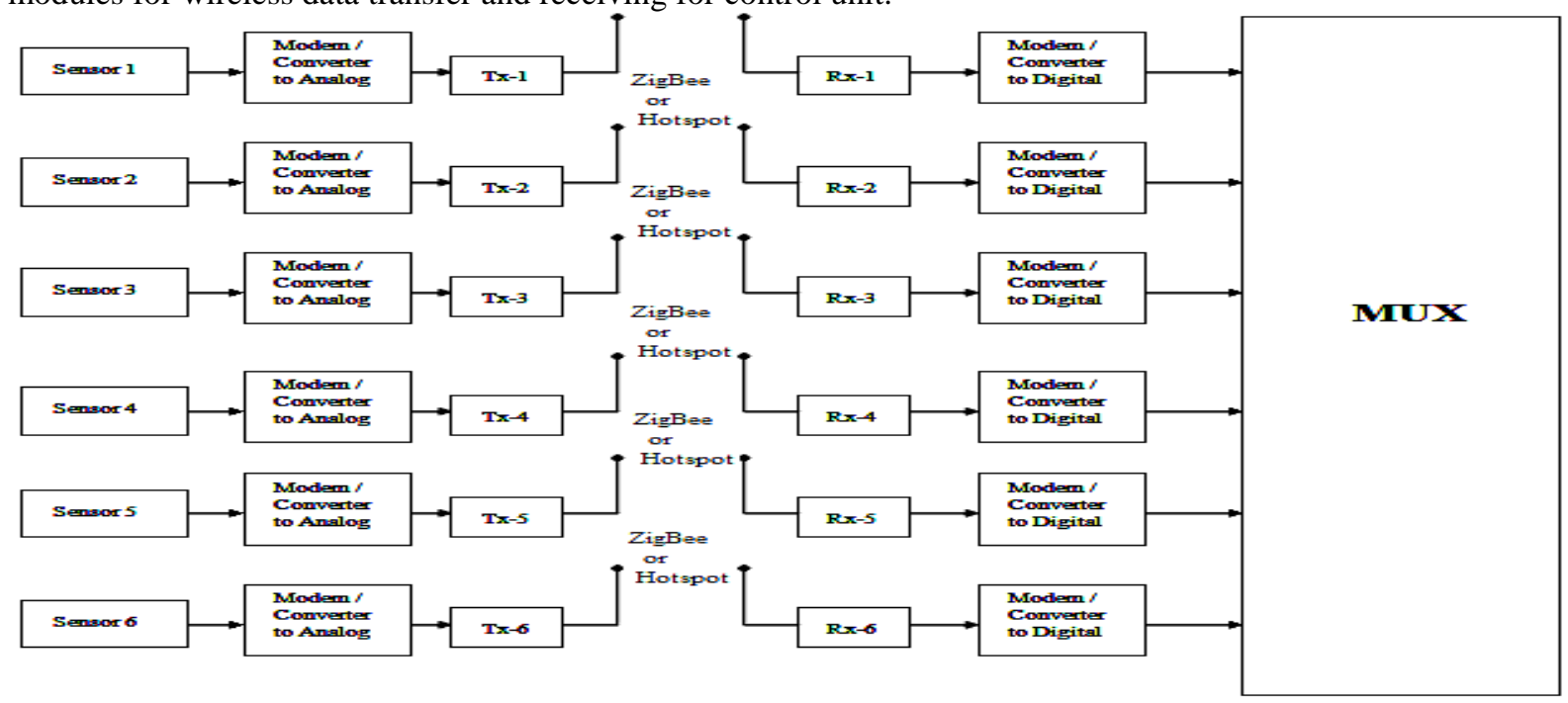

Fig. 1 Basic block diagram of proposed system (input part)

The block diagram of the proposed system of control unit is shown in Fig. 2 consists of data logger which 
allows count information to be associated with the date and time, and for the data to be downloaded onto a PC for flexible and detailed data analysis, Demultiplexer split a combined stream arriving from a shared medium into the original information streams and fed to different types of actuators such as drip irrigation pump, boring pump, fertilizer pump, controlling of pump speed, controlling of fertilizer input from the tank and display the field etc.

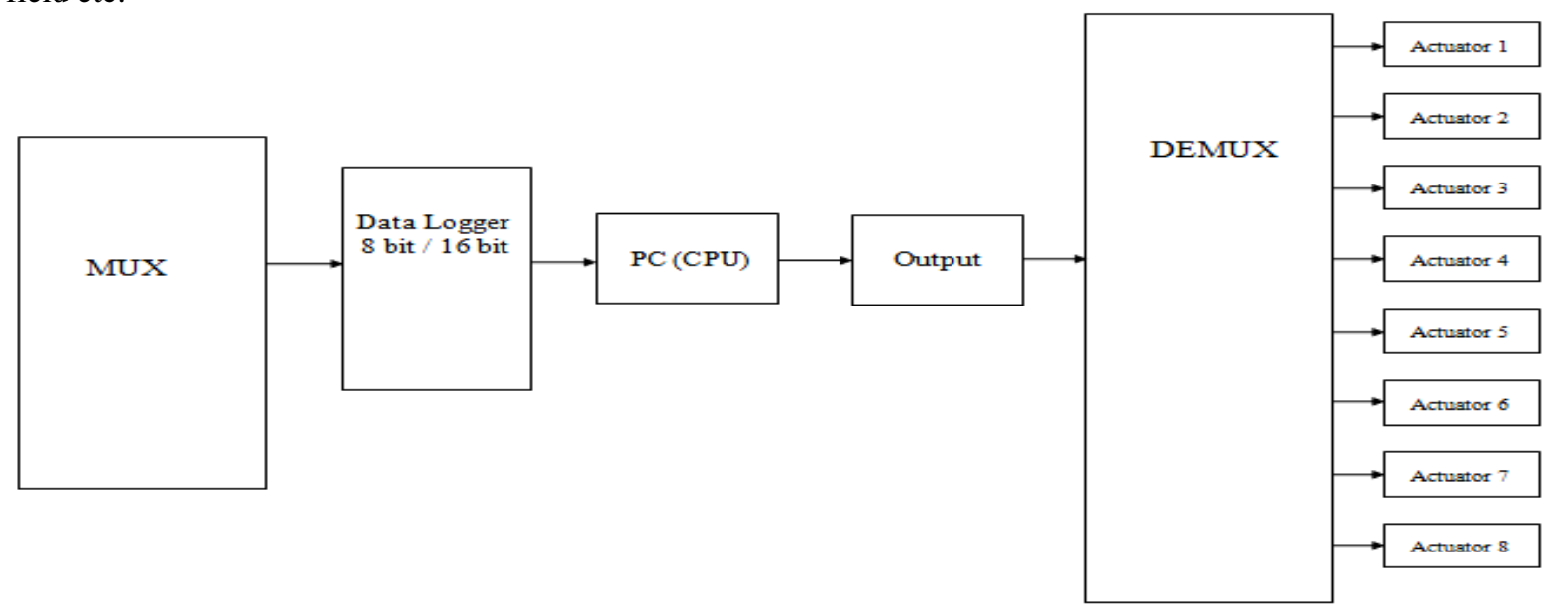

Fig. 2 Basic block diagram of proposed system (control unit)

\section{DICKE Radiometer}

A receiver of DICKE radiometer-type which detects weak signals in noise by modulating or switching the input signals before they reach conventional demodulation circuit.

The Dicke Radiometer was proposed to solve the stability problems of total power radiometers. A Dicke Radiometer views the scene during half of the cycle and a matched load during the other half of the cycle. In this case, instead of the antenna temperature the difference between the antenna temperature and a known reference value TR is measured.

$$
\text { Vout }=\mathrm{c}(\mathrm{TA}-\mathrm{TR}) \mathrm{G}
$$

Note that this radiometer is more stable than Total Power Radiometer since the output does not depend on TN and the weight of $\mathrm{G}$ can be diminished by choosing TR values in the range of TA. However, neglecting the gain fluctuations, the sensitivity of this configuration.

$$
\Delta T=2 \frac{T_{A}+T_{B}}{\sqrt{B T_{R}}}
$$

is degraded by a factor of 2 as compared to total power radiometers. The factor of two worse sensitivity arises from the fact that the scene is measured only half of the time.

For standardization in ground level of various leaf parameters, a system using radiometer can be utilized as described in the following diagram. Various leafs are placed and recording of Dicke Radiometer taken without any leaf and also with various leafs. This Lab system can be augmented to use it in farm field as and when required.

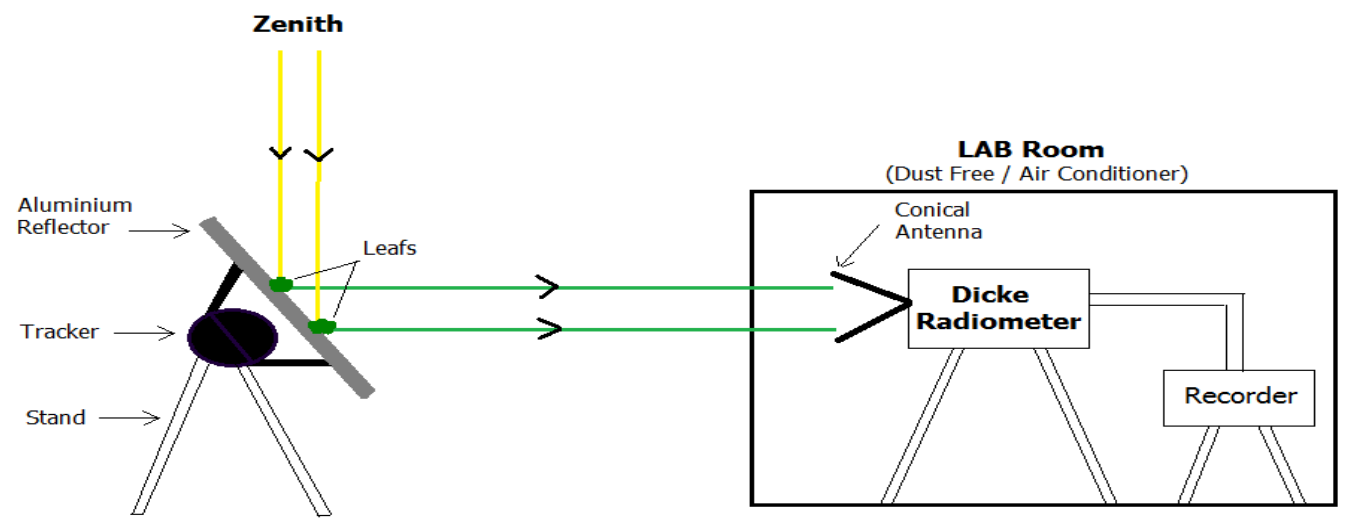

Fig. 3 Basic diagram for standardization in ground level of various leaf parameters (a system using radiometer)

\section{Optical Domain}

Optical remote sensing makes use of visible, near infrared and short-wave infrared sensors to form images of the 
earth's surface by detecting the solar radiation reflected from targets on the ground. Different materials reflect and absorb differently at different wavelengths. Thus, the targets can be differentiated by their spectral reflectance signatures in the remotely sensed images.

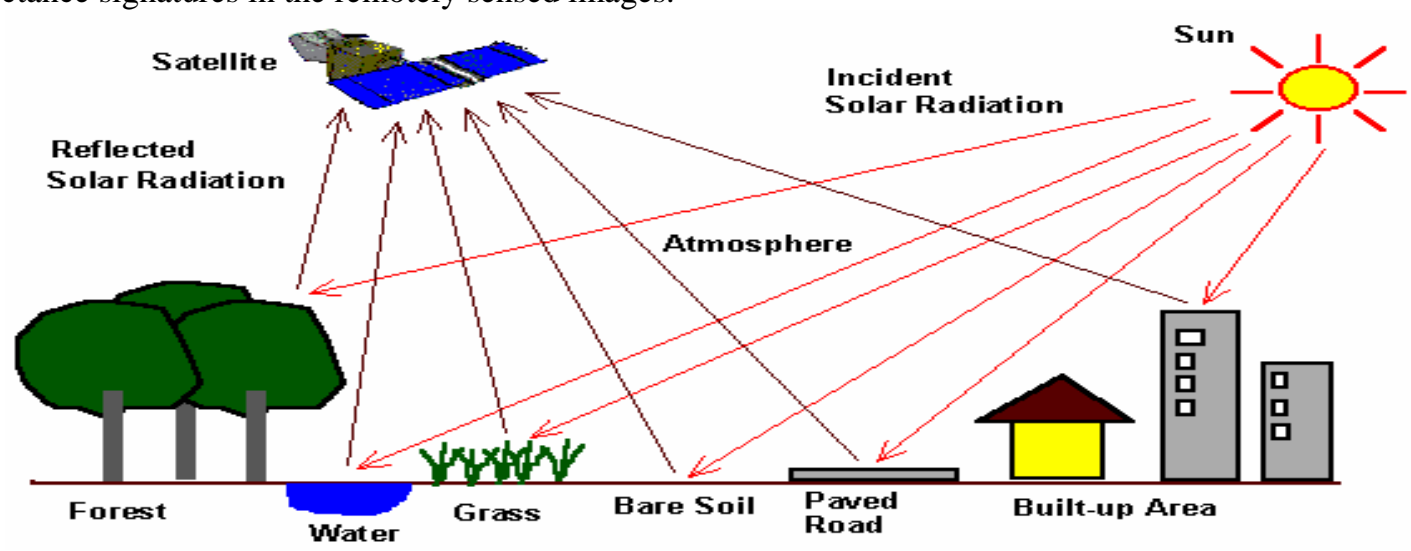

Fig. 4 Basic diagram of Optical Remote Sensing

Optical remote sensing systems are classified into the following types, depending on the number of spectral bands used in the imaging process.

Panchromatic imaging system: The sensor is a single channel detector sensitive to radiation within a broad wavelength range. If the wavelength range coincides with the visible range, then the resulting image resembles a "black-and-white" photograph taken from space. The physical quantity being measured is the apparent brightness of the targets. The spectral information or "color" of the targets is lost.

Multispectral imaging system: The sensor is a multichannel detector with a few spectral bands. Each channel is sensitive to radiation within a narrow wavelength band. The resulting image is a multilayer image which contains both the brightness and spectral (color) information of the targets being observed.

Super spectral Imaging Systems: A super spectral imaging sensor has many more spectral channels (typically >10) than a multispectral sensor. The bands have narrower bandwidths, enabling the finer spectral characteristics of the targets to be captured by the sensor.

Hyper spectral Imaging Systems: A hyper spectral imaging system acquires images in about a hundred or more contiguous spectral bands. The precise spectral information contained in a hyper spectral image enables better characterization and identification of targets. Hyper spectral images have potential applications in such fields as precision agriculture (e.g. monitoring the types, health, moisture status and maturity of crops).

The most practical, objective, and cost-effective way to monitor vegetation from a local to global scale is the use of Earth Observation technologies. Different sensors are currently onboard Earth Observation satellites that may be applicable to the monitoring of vegetation water content. These sensors can be separated into the following three categories.

(1) Visible to shortwave infrared (SWIR, spectrum between 400 and $2500 \mathrm{~nm}$ ). These provide information on vegetation biophysical parameters such as the chlorophyll content, the leaf area index, and the vegetation water content [49].

(2) Thermal infrared (spectrum between 6.0 and $15.0 \mathrm{~mm}$ ). These provide information on the thermal dynamics of vegetation cover. Thermal infrared has been used to estimate the evapotranspiration of vegetation canopies, a parameter that is closely related to water stress [35].

(3) Radar (spectrum between 0.1 and $100 \mathrm{~cm}$ ). These provide information on the dielectric constant which could be related to vegetation water content [34].

Vegetation status is also measured either by the Relative Drought Index (RDI) [21] or the Relative Water Content Index (RWC) [24]. RDI compares the actual Water Saturation Deficit (WSDact) with the critical threshold value for the Water Saturation Deficit (WSDcrit)

$$
R D I=\frac{\text { WSDact }}{\text { WSDcrit }}
$$

RWC compares the water content of a leaf with the maximum water content at full turgor.

$$
R W C=\frac{F W-D W}{T W-D W}
$$

where,

FW is the field weight, DW the oven dry weight, and TW the turgid weight.

In particular, the wavelengths at 1530 and $1720 \mathrm{~nm}$ seem to be most appropriate for assessing vegetation water [18]. In order to quantify directly vegetation water content, the following two definitions are classically used.

(i) The FMC defined as the ratio between the quantity of water (fresh weight-dry weight) and either the fresh 
weight [31] or the dry weight [4],[9]:

$$
F M C=\frac{F W-D W}{F W(O R D W)} X 100 \%
$$

where,

FW is the fresh weight measured in the field and DW the oven dry weight of the same sample.

(ii) The leaf water content per unit leaf area or EWT defined as the ratio between the quantity of water and the area. EWT corresponds to a hypothetical thickness of a single layer of water averaged over the whole leaf area [13]:

$$
E W T=\frac{F W-D W}{A}\left(\mathrm{~g} \mathrm{~cm}^{2}\right) \text { or }(\mathrm{cm})
$$

where,

A is the leaf area.[42]

By above method the leaf water content and health of plant growth can be estimated.

\section{Multi-Angular Spectroradiometer}

Another technique by using the remote sensing in a microwave \& millimeter-wave is by using a various angular spectral resolution. A microwave radiometric sensor is a device for the detection of electromagnetic energy which is noise-like in character. It is frequently referred to as a temperature measuring device, since the output indicator is calibrated in degree Kelvin. The physical rezoning in support of calibrating the output indicator of a microwave radiometer in degrees Kelvin can be derived from thermodynamic considerations and certain well-known properties of an antenna.

The amount of energy absorbed by an antenna and presented at the input terminals of the receiver depends upon the orientation of the antenna, the polarization of the wave, and the impedance match of the receiving system. Since all antennas are polarized, regardless of design, the maximum amount of energy accepted by an antenna, from a randomly polarized wave, is one-half of the total energy content of the wave. If we assume that an antenna is perfectly matched and that the incoming wave is randomly polarized with a power flux density S, then the absorbed power PA is given by the expression,

$$
P_{A}=\frac{1}{2} S A
$$

where,

$\mathrm{A}$ is the effective antenna aperture area.

$\&$ the flux density $\mathrm{S}$ is given by the expression,

$$
S=\frac{d E}{d A} d v \cdot d t
$$

which has the dimensions of power per unit area bandwidth.

Using an automated tower based spectroradiometer, we analyze the interactions between canopy level reflectance and different stages of disturbance occurring in a mountain pine beetle infested lodge pole pine stand. Canopy spectra were observed from an automated multi-angular spectroradiometer platform (AMSPEC), mounted at a height of $30.5 \mathrm{~m}$ on a $1.5 \mathrm{~m} \times 2.1 \mathrm{~m}\left(5^{\prime} \times 7^{\prime}\right)$ scaffold tower (Fig. 5A, B). AMSPEC was designed for high-frequency observations of canopy reflectance [20]. The instrument features a motor-driven probe that allows observations in a $290^{\circ}$ view area around the tower (the $70^{\circ}$ that cannot be observed are due to obstruction by the tower). The probe rotates in $11.5^{\circ}$ intervals every $30 \mathrm{~s}$, completing a full rotation every $15 \mathrm{~min}$. The exact position of the probe is determined using a potentiometer attached to the shaft of the motor. At the end of each sweep, the sensor is returned to its original position.
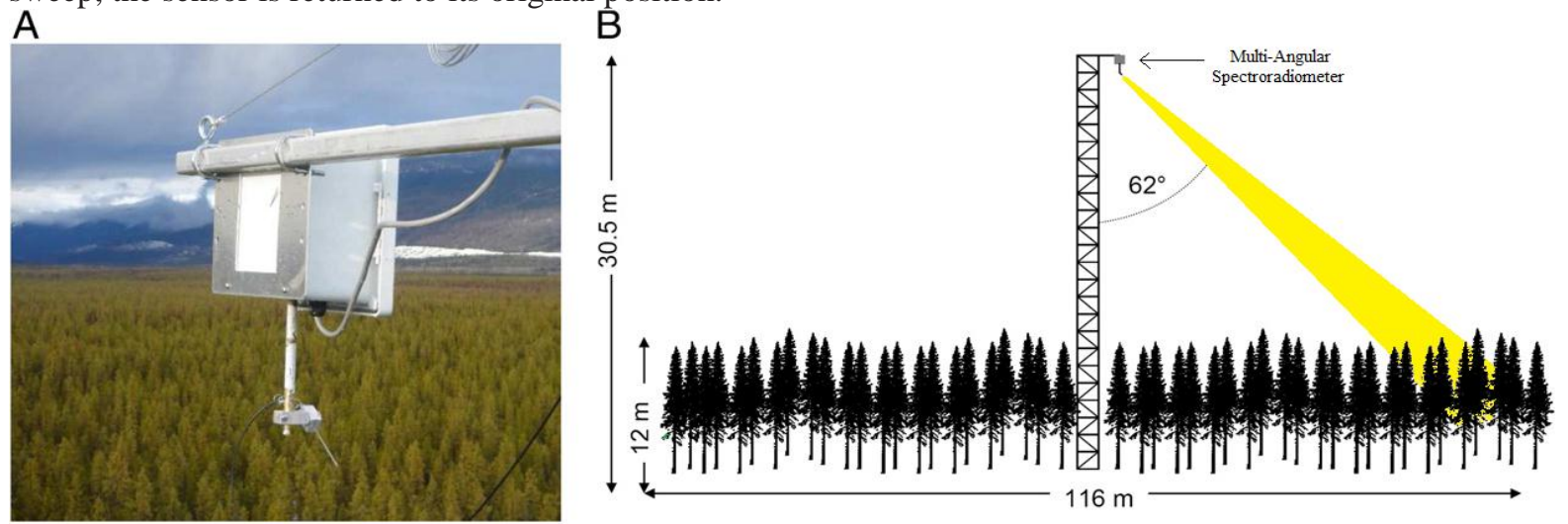

Fig. 5 A: Photograph of the tower mounted radiometer platform (AMSPEC) used to observed canopy 
reflectance changes due to mountain pine beetle attack. B: Setup and footprint of AMSPEC.

The spectroradiometer used is a Unispec-DC (PP Systems, Amesbury, MA, USA) featuring 256 contiguous bands with a nominal band spacing of $3 \mathrm{~nm}$ and a nominal range of operation between 350 and $1200 \mathrm{~nm}$ [20]. To allow sampling under varying sky conditions, canopy reflectance is obtained from simultaneous measurements of solar irradiance and radiance, sampled every $5 \mathrm{~s}$ from sunrise to sunset. The upward looking probe is equipped with a cosine receptor (PP-Systems) to correct sky irradiance measurements for varying solar altitudes. The downward looking probe measures canopy radiance at a zenith angle of $62^{\circ}$ to account for canopy clumping [7] and to minimize background reflectance effects. The probe's instantaneous field of view (IFOV) is $20^{\circ}$, or approximately $33 \times 7 \mathrm{~m}$ at canopy height. The instrument's footprint results from its setup geometry and comprises an outer diameter of about $116 \mathrm{~m}$ while the inner diameter is about $46 \mathrm{~m}$. A complete technical description of the instrument its software, setup and calibration can be found in [20], [47].

\section{Conclusions \& Future scope}

It can be concluded that the modern use of electronic, electrical, chemical and mechanical systems will be very advantages for better agricultural output. Remote sensing techniques using optical methodology and micro-wave and millimeter wave radiometric data for crop growth, soil nature and crop forecast can be adopted and there is a huge scope to advance in various approaches in this direction. Preservation of water sources and minimizing the use of inorganic fertilizer are possible with these methods. Use of bio-fertilizer in appropriate manner will find better guiding parameters through the various sensing methods. In this age of population explosion the huge demand of food can be met with this state of the art process.

This study has shown that information on vegetation water content in terms of EWT at the leaf level can be retrieved from leaf reflectance measurements. Remote sensing using the thermal infrared, the visible and NIR wavelength ranges alone or in established vegetation indices was demonstrated unsuitable for retrieving vegetation water content at the leaf level.

To keep the environmental balance of various sources of this planet and maintaining the methane generation during harvesting under control, this modern approach will help to reach a target with more modern gadgets. In future days to come, we can even apply food nutrients to the plant and crop by air mixed with very less water, with better monitoring and processing.

\section{References}

[1] Alonso, M., Camarasa, A., Chuvieco, E., Cocero, D., Kyun, I. A., Martin, M. P., \& Salas, F. J. (1996). Estimating temporal dynamism of fuel moisture content of mediterranean species from NOAA-AVHRR data. EARSeL Advances in Remote Sensing, 4 (4), 9- 24

[2] Baggio A (2005). Wireless sensor networks in precision agriculture. In: On-line Proc, of the Workshop on Real-World Wireless Sensor Networks, pp. 50-51.

[3] Balendonck J, Hemming J, Van Tuijl BAJ, Pardossi A, Incrocci L, Marzialetti P (2008). Sensors and Wireless Sensor Networks for Irrigation Management under Deficit Conditions (FLOW-AID). International Conference on Agricultural Engineering (AgEng2008). Conf. Proc. p.19.

[4] Burgan, R. E. (1996). Use of remotely sensed data for fire danger estimation. EARSeL Advances in Remote Sensing, 4 (4), $1-8$.

[5] Camilli A, Cugnasca CE, Saraiva AM, Hirakawa AR, Corrêa LP (2007). From wireless sensor to field mapping: Anatomy of an application for precision agriculture. Comput. Electron. Agric., 58: 25-36

[6] Chapin, F. S., Trainor, S. F., Huntington, O., Lovecraft, A. L., Zavaleta, E., Natcher, D. C., McGuire, A. D., Nelson, J. L., Ray, L., Calef, M., Fresco, N., Huntington, H., Rupp, T. S., Dewilde, L., \& Naylor, R. L. (2008). Increasing wildfire in Alaska's boreal forest: Pathways to potential solutions of a wicked problem. BioScience, 58, 531-540.

[7] Chen, J., \& Black, T. (1991). Measuring leaf area index of plant canopies with branch architecture. Agricultural and Forest Meteorology, 57, 1-12.

[8] Cheney, P., \& Sullivan, A. (1997). Grassfires fuel, weather and fire behaviour (p. 102). PO Box 1139 (150 Oxford Street) Collingwood 3066, Australia: CSIRO Publishing.

[9] Chuvieco, E., Deshayes, M., Stach, N., Cocero, D., \& Riaño, \&. (1999). Short-term fire risk: foliage moisture content estimation from satellite data. In: E. Chuvieco (Ed.), Remote sensing of large wildfires in the European Mediterranean Basin (p. 228). Berlin: Springer (University of Alcala', Spain).

[10] Coates RW, Delwiche M, Brown P (2005). Precision Irrigation in Orchards: Development of a Spatially Variable Micro sprinkler System. Information and Technology for Sustainable Fruit and Vegetable Production (FRUTIC). pp. 611-624.

[11] Coates RW, Delwiche MJ, Brown PH (2006a). Control of individual micro sprinklers and fault detection strategies. Precision Agric., 7: 85-99.

[12] Coates RW, Delwiche MJ, Brown PH (2006b). Design of a system for individual micro sprinkler control. Trans. ASABE, 49(6): 1963-1970.

[13] Danson, F. M., Steven, M. D., Malthus, T. J., \& Clark, J. A. (1992). Highspectral resolution data for determining leaf water content. International Journal of Remote Sensing, 13 (3), 461-470.

[14] Doraiswamy PC, Hatfield JL, Jackson TJ, Akhmedov B, Prueger J, Stern A (2004). Crop condition and yield simulations using Landsat and MODIS. Remote Sensing Environ., 92: 548-559.

[15] Dursun M, Ozden S (2010). A Prototype of PC Based Remote Control of Irrigation. International Conference on Environmental Engineering and Application (ICEEA), pp. 255-258. (IEEE Catalog Number: CFP1020L-PRT) 
[16] Eidenshink, J. C., Burgan, R. E., \& Haas, R. H. (1990). Monitoring fire fuels condition by using time series composites of Advanced Very High Resolution Radiometer (AVHRR) Data. Proceedings of Resource Technology 90 ( pp. 68- 82). Washington, DC: ASPRS.

[17] Engman ET, Chauhan N (1995). Status of microwave soil moisture measurements with remote sensing. Remote Sensing Environ., 51: $189-198$

[18] Fourty, T., \& Baret, F. (1997). Vegetation water and dry matter contents estimated from top-of-the-atmosphere reflectance data: a simulation study. Remote Sensing of Environment, 61, 34-45.

[19] Ge Jianjun, Wang Chao, Zhang Weiguo, 2002. Review of vegetation scattering model in soil moisture microwave remote sensing. Remote Sensing Technology and Application, 17(4): 209-214. (in Chinese).

[20] Hilker, T., Coops, N. C., Nesic, Z.,Wulder,M. A., \& Black, A. T. (2007). Instrumentation and approach for unattended year round tower based measurements of spectral reflectance. Computers and Electronics in Agriculture, 56, 72-84.

[21] Ho"fler, K., Migsch, H., \& Rottenburg, W. (1941). U“ ber die Austrocknungsresistenz landwirtschaftlicher Kulturpflanzen. Forschungsdienst, 12, 50-61.

[22] Houghton, R. A. (1999). The annual net flux of carbon to the atmosphere from changes in land use 1850-1990. Tellus Series BChemical and Physical Meteorology, 51, 298-313.

[23] Illera, P., Fernandez, A., \& Delgado, J. A. (1996). Temporal evolution of the NDVI as an indicator of forest fire danger. International Journal of Remote Sensing, 17 (6), 1093- 1105.

[24] Inoue, Y., Morinaga, S., \& Shibayama, M. (1993). Non-destructive estimation of water status of intact crop leaves based on spectral reflectance measurements. Japan Journal of Crop Science, 62 (3), 462- 469.

[25] Jackson TJ, Vine DL, Hsu AY, Oldak A, Starks P, Swift C, Isham J, Haken M (1999). Soil moisture mapping at regional scales using microwave radiometry: the Southern Great Plains Hydrology Experiment. IEEE Trans. Geosci. Remote Sensing, 37:21362151 .

[26] Kim Y, Evans RG (2009). Software design for wireless sensor-based site-specific irrigation. Comput. Electron. Agric., 66: 159-165

[27] Kim Y, Evans RG, Iversen WM (2008). Remote sensing and control of an irrigation system using a distributed wireless sensor network. IEEE Trans. Instrum. Meas., 57(7): 1379-1387.

[28] Kurz,W. A., Dymond, C. C., Stinson, G., Rampley, G. J., Neilson, E. T., Carroll, A. L., Ebata, T., \& Safranyik, L. (2008). Mountain pine beetle and forest carbon feedback to climate change. Nature, 452, 987-990.

[29] Larcher, W. (1995). Physiological plant ecology. Ecophysiology and stress physiology of functional groups (3rd ed.) p. 528. New York: Springer.

[30] Masek, J. G., Huang, C. Q., Wolfe, R., Cohen, W., Hall, F., Kutler, J., \& Nelson, P. (2008). North American forest disturbance mapped from a decadal Landsat record. Remote Sensing of Environment, 112, 2914-2926.

[31] Mbow, C. (1999). Proposition of a method for early fires planning using ground and satellite (NDVI/NOAA-AVHRR) data from Niokolo Koba National Park (Southeast Senegal). Poster Presentation in Proceedings of the Second International Symposium on Operationalization of Remote Sensing, 16-20 August 1999, ITC, Enschede, The Netherlands.

[32] Mendoza-Jasso J, Vargas GO, Miranda RC, Ramos EV, Garrido AZ, Ruiz GH (2005). FPGA-based real-time remote monitoring system. Comput. Electron. Agric., 49: 272-285.

[33] Miranda FR, Yoder R, Wilkerson JB (2003).A site-specific irrigation control system. ASAE Annual International Meeting.p. 031129.

[34] Moghaddam, M., \& Saatchi, S. S. (1999). Monitoring tree moisture using an estimation algorithm applied to SAR data from BOREAS. IEEE Transactions on Geoscience and Remote Sensing, 17 (2), 901-916.

[35] Moran, M. S., Clarke, T. R., Inoue, Y., \& Vidal, A. (1994). Estimation crop water deficit using the relation between surface- air temperature and spectral vegetation index. Remote Sensing of Environment, 49, 246- 263.

[36] Oksanen T, Ohman M, Miettinen M, Visala A (2004). Open configurable control system for precision farming. Automation Technology for Off-Road Equipment, Proceedings, 701P1004.

[37] Pacala, S. W., Hurtt, G. C., Baker, D., Peylin, P., Houghton, R. A., Birdsey, R. A., Heath, L., Sundquist, E. T., Stallard, R. F., Ciais, P., Moorcroft, P., Caspersen, J. P., Shevliakova, E., Moore, B., Kohlmaier, G., Holland, E., Gloor, M., Harmon, M. E., Fan, S. M., Sarmiento, J. L., Goodale, C. L., Schimel, D., \& Field, C. B. (2001). Consistent land- and atmosphere-based US carbon sink estimates. Science, 292, 2316-2320.

[38] Paltridge, G. W., \& Mitchell, R. M. (1990). Atmospheric and viewing angle correction of vegetation indices and grassland fuel moisture content derived from NOAA/AVHRR. Remote Sensing of Environment, 31, 121- 135.

[39] Paltridge, G.W., \& Barber, J. (1988). Monitoring grassland dryness and fire potential in Australia with NOAA/AVHRR data. Remote Sensing of Environment, 25, 381-394.

[40] Panchard J, Rao S, Prabhakar TV, Jamadagni HS, Hubaux JP (2006). COMMON-Sense Net: Improved Water Management for Resource-Poor Farmers via Sensor Networks. ICTD 2006 Conference.

[41] Peñuelas, J., Filella, I., Biel, C., Serrano, L., \& Save', R. (1993). The reflectance at the $950-970 \mathrm{~nm}$ region as an indicator of plant water status. International Journal of Remote Sensing, 14 (10), 1887- 1905.

[42] Pietro Ceccato, Stephane Flasse, Stefano Tarantola, Stephane Jacquemoud, Jean-Marie Gregoire(2001). Detecting vegetation leaf ater content using reflectance in the optical domain. Remote sensing of environment, 77, 22-33.

[43] Sezen SM, Celikel G, Yazar A, Tekin S, Kapur B (2010). Effect of irrigation management on yield and quality of tomatoes grown in different soilless media in a glasshouse. Sci. Res. Essay, 5(1): 41-48.

[44] Siuli Roy AD, Bandyopadhyays S (2008). Agro-sense: Precision agriculture using sensor-based wireless mesh networks. Innovations in NGN: Future Network and Services. In: Proceedings of the First ITU-T Kaleidoscope Academic Conference (KINGN 2008). pp. 383-388.

[45] Soja, A. J., Tchebakova, N. M., French, N. H. F., Flannigan, M. D., Shugart, H. H., Stocks, B. J., Sukhinin, A. I., Varfenova, E. I., Chapin, F. S., \& Stackhouse, P. W. (2007). Climateinduced boreal forest change: Predictions versus current observations. Global and Planetary Change, 56, 274-296.

[46] Song Dongsheng, Zhao Kai, Guan Zhi (2007). Advances in Research on soil Moisture by Microwave Remote Sensing in China. Chinese Geographical Science, 17(2), 186-191.

[47] Thomas Hilker, Nicholas C. Coops, Samuel B. Coggins, Michael A. Wulder, Mathew Brownc, T. Andrew Black, Zoran Nesic, Dominic Lessard(2009). Detection of foliage conditions and disturbance from multi-angular high spectral resolution remote sensing. Remote sensing of environment, 113, 421-434.

[48] Tucker, C. J. (1977). Asymptotic nature of grass canopy spectral reflectance. Applied Optics, 16 (5), 1151- 1156

[49] Tucker, C. J. (1980). Remote sensing of leaf water content in the nearinfrared. Remote Sensing of Environment, 10, $23-32$.

[50] Ulaby FT, Dubois PC, Zyl JJV (1996). Radar mapping of surface soil moisture. J. Hydrol., 184: 57-84. 
[51] Vellidis G, Tucker M, Perry C, Kvien C, Bednarz C (2008). A real-time wireless smart sensor array for scheduling irrigation. Comput. Electron. Agric., 61: 44-50.

[52] Wang N, Zhang N, Wang M (2006). Wireless sensors in agriculture and food industry - Recent development and future perspective. Comp. Electron. Agric., 50: 1-14.

[53] Westerling, A. L., \& Bryant, B. P. (2008). Climate change and wildfire in California. Climatic Change, 87, S231-S249.

[54] Zhang Z (2004). Investigation of wireless sensor networks for precision agriculture. ASAE Annual International Meeting. p. 041154 . 